\title{
REMOVAL OF PHOSPHORUS FROM SYNTHETIC WASTEWATER USING RECYCLED CONCRETE AGGREGATES AS A FILTER MEDIUM
}

\author{
S. H. Adnan ${ }^{1}$, R. Hamdan ${ }^{2}$, N.I.M. Yassin' ${ }^{2}$ and N. A. Roni ${ }^{1}$ \\ ${ }^{1}$ Department of Civil Engineering Technology, Faculty of Engineering Technology, Universiti Tun Hussein Onn Malaysia \\ 86400 Parit Raja, Batu Pahat, Johor, Malaysia \\ ${ }^{2}$ Department of Water and Environmental Engineering, Faculty of Civil and Environmental Engineering, Universiti Tun \\ Hussein Onn Malaysia, Batu Pahat, Johor Malaysia
}

Date received: 07/01/2018, Date accepted: 25/03/2018

Corresponding author's email: suraya@uthm.edu.my

\begin{abstract}
These days, sustainability has become a primary concern as the large amount of natural resources are being used to produce materials such as concrete. Concrete from the construction industry constitutes the major proportion of construction waste. This could bring negative impact including depletion of natural resources, pollution, increasing landfill space, and high cost of waste disposal. All of these negative impacts are the sustainability issues that should be concentrated on. Hence, alternative methods have been introduced in order to reduce waste by recycling concrete waste. One of the alternative methods that can be used is by reusing recycled concrete aggregates (RCA) from discarded waste cubes. RCA can be used to produce new concrete but it will generally have a lower performance compared to normal concrete. Thus, the present study introduces an alternative method which is by reusing the RCA as a water filter medium to remove phosphorus from wastewater. Phosphorus is one of the inorganic compounds found in wastewater that can lead to environmental problems such as eutrophication. Based on previous studies, many types of materials with various chemical compositions have been used for phosphorus removal from wastewater. Therefore, this study demonstrates the ability of RCA as an alternative method for phosphorus removal from wastewater. In addition, three different factors have been considered in the removal of phosphorus namely, different initial concentration of phosphorus, different sizes of RCA and dosage of RCA used during the treatment process. Based on the experiments conducted, the lowest initial concentration of phosphorus of $10 \mathrm{mg} / \mathrm{L}$, the smallest RCA size ranging between $0 \mathrm{~mm}$ to $5 \mathrm{~mm}$ and the highest RCA dosage of $50 \mathrm{~g}$ resulted in the highest percentage of phosphorus removal in wastewater.
\end{abstract}

Copyright $\odot 2018$ UNIMAS Publisher. This is an open access article distributed under the Creative Commons Attribution-NonCommercial-ShareAlike 4.0 International License which permits unrestricted use, distribution, and reproduction in any medium, provided the original work is properly cited.

Keywords: Phosphorus, recycled aggregates, recycled concrete aggregates, wastewater treatment, synthetic wastewater

\subsection{INTRODUCTION}

Sustainability concerns nowadays have become one of the main issues as the usage of natural resources keeps increasing from time to time. For example, the construction industry has contributed to the largest usage of natural resources for producing materials such as concrete. Besides the high usage of natural resources, the construction industry also produces a lot of waste that could also bring negative impacts to the environment.

According to Defra [1], about $32 \%$ of waste from the construction and demolition (C\&D) process are produced in United Kingdom. The government has set up the Sustainable Construction Strategy to reduce construction waste by $50 \%$. One of the $C \& D$ wastes is concrete cubes. During the last decade, the construction sector has seen a growing trend in construction and demolition (C\&D) activities. The management of collected debris and waste causes real problems at the environmental level. Due to sustainability concerns, the concrete cubes generated may be recycled or reused in order to reduce the usage of natural resources. The concrete cubes can be recycled by reusing the aggregates inside the concrete to produce new concrete. Recycled Concrete Aggregates (RCA) consist of stone particles attached to old cement mortar generated in the process of demolition [2].

According to the Federal Highway Administration (FHWA), large amounts of waste materials produced have caused a reduction in available landfill space in some areas in the United States [3]. It is estimated that the construction waste produced as a result of building demolition is about 123 million tonnes every year. The major source of concrete waste produced comes from the demolition of structures and roadways. Hence, the recycling of waste materials especially demolished concrete may lessen the amount of raw materials needed for construction. The cost benefits for using RCA in some regions of the United States 
may materialise into savings of $20 \%$ to $30 \%$ compared to natural aggregates [4]. The FHWA has noted that many states have high tipping fees for the disposal of RCA [3].

Instead of producing new concrete, recycled aggregates can also be used as a filter medium. This is because RCA has a lower performance compared to normal concrete [5]. Therefore, this project focuses on RCA as a wastewater filter medium as an alternative method for wastewater treatment. More specifically, RCA was used in this study to remove phosphorus which is one of the inorganic compounds in wastewater.

According to Vymazal et al.,[6] phosphorus can be a source of pollution. It can lead to eutrophication which is one of the environmental problems faced by the world these days. According to previous studies, different types of naturally occurring materials such as minerals and rocks, soils and marine sediments have been tested for phosphorus removal. Hence, this study presents another type of material for phosphorus removal in wastewater namely, RCA obtained from discarded waste cubes at the Material Laboratory in Universiti Tun Hussein Onn Malaysia. In the construction field, concrete is the main construction material across the world and is mostly used in all types of civil engineering work. An aggregate represents about $70-80 \%$ of concrete components. Thus, it will eventually lead to construction waste. Therefore, it will be beneficial to recycle the aggregate in order to solve environmental problems. To minimise the problem of excess waste materials, it is wise to utilise recycled aggregates. Next, another problem is due to eutrophication. Eutrophication of freshwater bodies is one of the main problems faced by aquatic ecosystems. In developing countries, approximately $75 \%$ of domestic wastewater is released to the environment without treatment. Thus, in this study, recycled concrete aggregate (RCA) was chosen as one of the materials for the absorption of phosphorus using a horizontal aerated filter.

\subsection{EXPERIMENTAL STUDY}

Materials used in this study were RCA and synthetic wastewater. The RCA used was obtained from discarded waste cubes collected from the Material Laboratory in UTHM as shown in Figure 1. The waste cubes were normal concrete cubes without any additives. The waste cubes were crushed by using cube crushing machines (Concrete crusher - A35399) as shown in Figure 2 in order to produce the aggregates. Later on, all the aggregates were separated according to the size needed. All the aggregates were categorised into three different sizes namely, less than $5 \mathrm{~mm}, 5-10 \mathrm{~mm}$, and 10-20 $\mathrm{mm}$ by using the sieve analysis process.

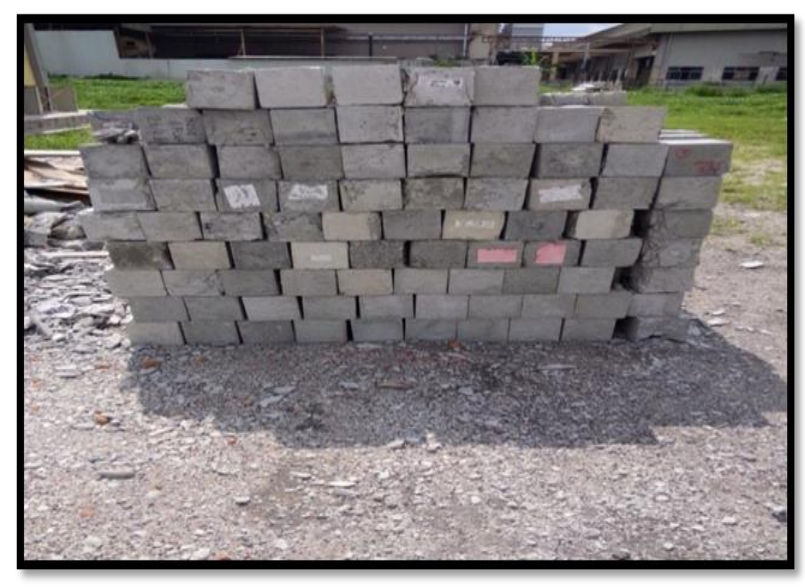

Figure 1 Thrown waste cubes from the Material Laboratory, UTHM 


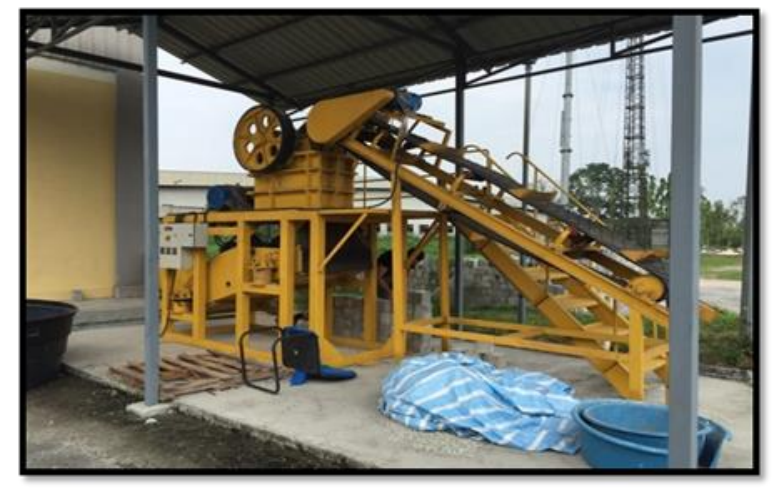

Figure 2 Cube crushing machine (Concrete crusher - A35399)

As for the synthetic wastewater, it was prepared before the experiment was conducted. The synthetic wastewater was prepared using Potassium Dihydrogen Phosphate $\mathrm{KH}_{2} \mathrm{PO}_{4}$. For the preparation of synthetic wastewater, $4.391 \mathrm{~g}$ of $\mathrm{KH}_{2} \mathrm{PO}_{4}$ was weighed and put into a $1 \mathrm{~L}$ volumetric flask. Then, distilled water was poured into the volumetric flask until it reached a volume of $1 \mathrm{~L}$ in order to produce 1000 $\mathrm{mg} / \mathrm{L}$ of phosphorus concentration. Then, the mixture was mixed thoroughly. The synthetic wastewater was prepared in three different initial concentrations which were $10 \mathrm{mg} / \mathrm{L}, 20 \mathrm{mg} / \mathrm{L}$ and $30 \mathrm{mg} / \mathrm{L}$. The preparation of the different initial concentrations of phosphorus was based on the equation 1 .

$$
\mathrm{M}_{1} \mathrm{~V}_{1}=\mathrm{M}_{2} \mathrm{~V}_{2}
$$

where;

$\mathrm{M}_{1}=$ Concentration of prepared stock solution

$\mathrm{M}_{2}=$ Designed concentration (concentration

needed)

$\mathrm{V}_{1}=$ Amount to be taken from stock solution

$\mathrm{V}_{2}=$ Volume of volumetric flask used

In order to produce different initial concentrations of phosphorus in synthetic wastewater, specific amounts of stock solution should be taken and mixed with distilled water. The calculation of volume to be taken from the stock solution is as follows:

$10 \mathrm{mg} / \mathrm{L}$ of initial concentration of phosphorus:

$\mathrm{V}_{1} \quad=2.5 \mathrm{ML}$

$20 \mathrm{mg} / \mathrm{L}$ of initial concentration of phosphorus:

$\mathrm{V}_{1} \quad=5 \mathrm{ML}$

$30 \mathrm{mg} / \mathrm{L}$ of initial concentration of phosphorus:

$\mathrm{V}_{1} \quad=7.5 \mathrm{ML}$

\subsection{XRF ANALYSIS OF RCA}

$8 \mathrm{~g}$ of the grounded sample (RCA) was weighed and put into a beaker. $2 \mathrm{~g}$ of $\mathrm{Lico}\left(\mathrm{CH}_{2}\right)$ wax was weighed and put into the same beaker and mixed thoroughly. Then, the die set was assembled. Firstly, the barrel and the base were assembled. Secondly, the polished steel pellet was placed in the bore of the die base. The mixed sample was put into the sample die set. Thirdly, a die steel pellet was inserted with the polished surface facing the sample but the pellet was not pushed while it was falling slowly. Then the plunger was inserted into the smooth area facing the steel pellet. The die set was by now completely assembled. Fourthly, the assembled die set was transferred to the press. The valve was turned to press position and the lever was swung up to start pressing and stop swinging when the pressure gauge reached 
approximately $15 \mathrm{~N}$. Afterwards, it was left for five minutes and the valve was slowly turned to venting position. The top bolster was then unscrewed to take the die set out from the sample press. The die base was then removed from the barrel. After that, the black up is then inserted to the bottom of die barrel. Next, it was put to the press and the top bolster was screwed until the plunger moved down. The die was then taken out from the press and the die barrel and plunger were removed. Lastly, the steel pellets were taken out from the black up and all the samples were taken out. Figure 3 and 4 show the apparatus used for the analysis and the RCA sample respectively.

Johanson [7] studied the ability of different natural materials used as filter substrates for P-removal in wastewater treatment. Among natural materials used were dolomite, limestone, opoka, wollastonite, bauxite and zeolites. All these materials were used to remove $\mathrm{P}$ from wastewater.

The findings of his study showed that the total sorption of $\mathrm{P}$ by limestone was between $0.25-0.3 \mathrm{mg} / \mathrm{kg}$ while the P-sorption by blast furnace slag was between $0.15-0.4 \mathrm{mg} / \mathrm{kg}$. These natural materials have some similarities in chemical composition which facilitate the absorption of $\mathrm{P}$ in wastewater. Most of the materials contain a high amount of $\mathrm{Si}, \mathrm{Ca}, \mathrm{Al}-$, and $\mathrm{Fe}$ - where these chemical compositions easily react with $\mathrm{P}$. Based on the XRF analysis conducted for RCA, it was shown that RCA also contains a high $\mathrm{SiO}_{2}$ concentration of $57.20 \%, 11.60 \%$ of $\mathrm{CaO}, 3.99 \%$ of $\mathrm{Al}_{2} \mathrm{O}_{3}$ and $2.13 \%$ of $\mathrm{Fe}_{2} \mathrm{O}_{3}$. This shows that RCA could also be one of the potential substrates for P-removal in wastewater treatment process. Table 1 shows the chemical composition of RCA based on the XRF analysis.

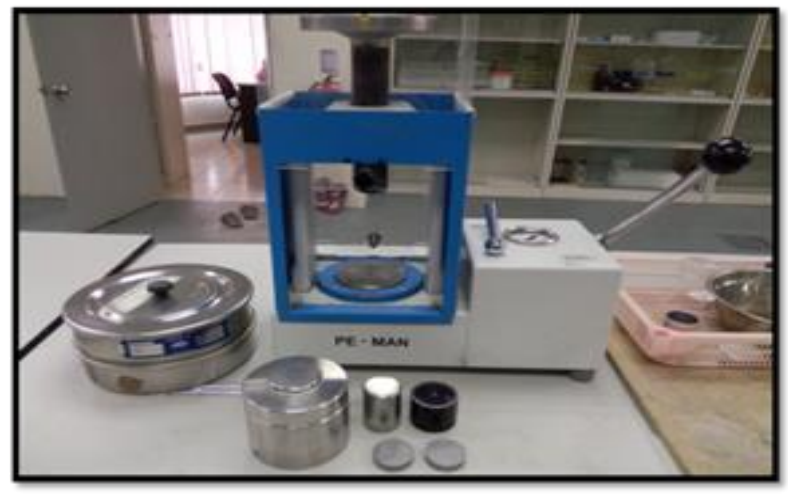

Figure 3 Apparatus for XRF analysis

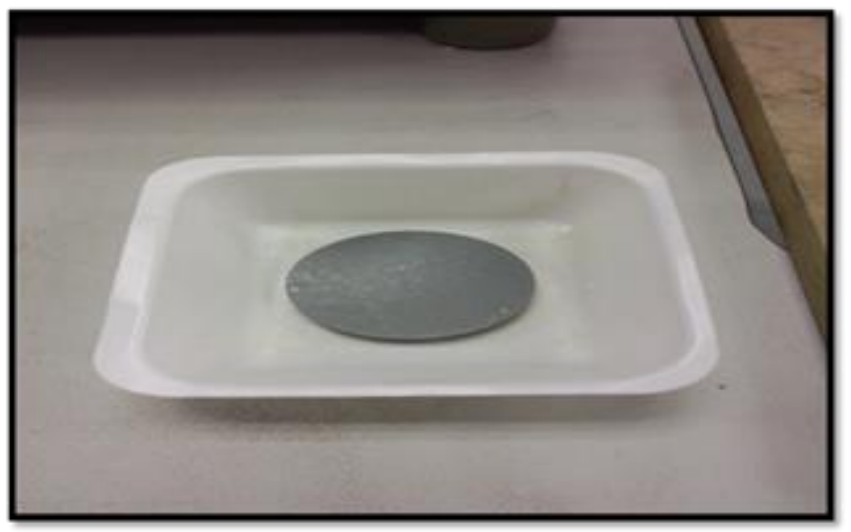

Figure 4 Sample of RCA 
Table 1 Chemical Composition of RCA

\begin{tabular}{lc}
\hline Formula & Concentration \\
\hline $\mathrm{SiO} 2$ & $57.20 \%$ \\
$\mathrm{CaO}$ & $11.60 \%$ \\
$\mathrm{~A} 2 \mathrm{O} 3$ & $3.99 \%$ \\
$\mathrm{Fe} 2 \mathrm{O} 3$ & $2.13 \%$ \\
$\mathrm{C}$ & $1.00 \%$ \\
$\mathrm{~K} 2 \mathrm{O}$ & $0.98 \%$ \\
$\mathrm{SO} 3$ & $0.60 \%$ \\
\hline
\end{tabular}

\subsection{ENERGY DISPERSIVE X-RAY SPECTROSCOPY (EDX) OF RCA}

Cement paste contains a high amount of $\mathrm{Ca}$. This could verify that the highest dosage of RCA removed the highest amount of $\mathrm{P}$. This is because the higher the calcium content, the higher the ability for phosphorus removal. Besides, the RCA also contains aluminium and magnesium which enhance phosphorus adsorption. Moreover, RCA also contains the Phosphorus (P) element which shows that RCA has a high capacity for absorbing phosphorus. After a few months in the aerated filter system, phosphorus can be seen on the surface of RCA samples after being examined using EDX. Figures 5 shows the presence of phosphorus on the surface of RCA through EDX mapping and the spectrum analysis of surface RCA samples after a two-month period of the treatment.

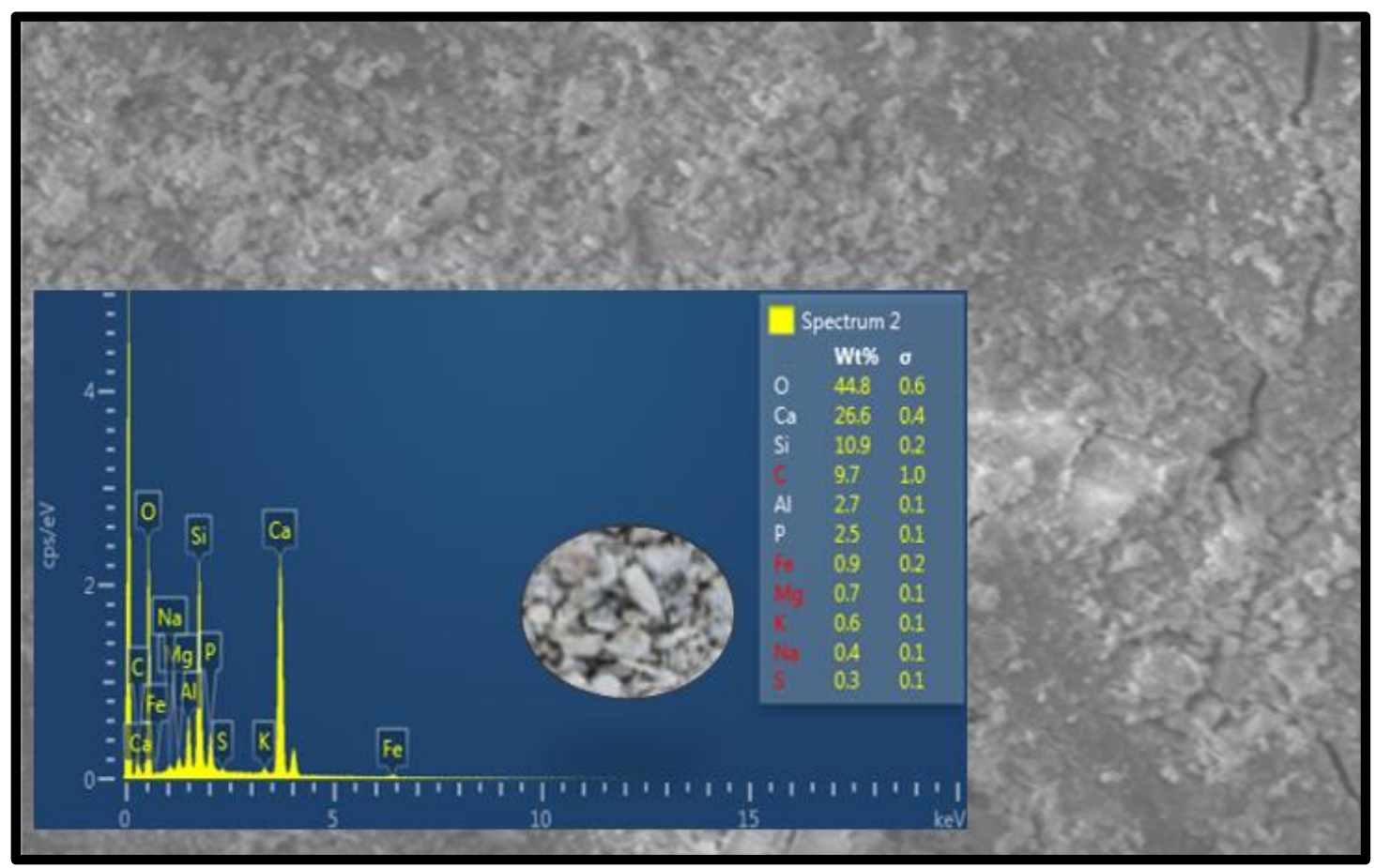

Figure 5 EDX testing of RCA

\subsection{BATCH EXPERIMENT PROCESS}

For this study, a batch experiment was conducted for the wastewater treatment process. The treatment process was conducted using beakers, three different sizes (below $5 \mathrm{~mm}, 5-10 \mathrm{~mm}, 10-20 \mathrm{~mm}$ ) and 
dosages (10 g, $30 \mathrm{~g}, 50 \mathrm{~g})$ of RCA and synthetic wastewater with different initial concentrations (10 $\mathrm{mg} / \mathrm{L}, 20 \mathrm{mg} / \mathrm{L}, 30 \mathrm{mg} / \mathrm{L}, 40 \mathrm{mg} / \mathrm{L}, 50 \mathrm{mg} / \mathrm{L}$ ) of phosphorus. The following paragraphs describe the steps in the wastewater treatment process.

First of all, four beakers were cleaned using tap water, distilled water and hydrochloric acid ( $\mathrm{HCl})$ to avoid any contamination inside the beakers. Then, three sets of $250 \mathrm{ml}$ of synthetic wastewater with initial phosphorus concentrations of $10 \mathrm{mg} / \mathrm{L}, 20 \mathrm{mg} / \mathrm{L}$ and $30 \mathrm{mg} / \mathrm{L}$ respectively were inserted into three different beakers while $250 \mathrm{ml}$ of distilled water (blank) was inserted into the forth conical flask as the control media.

Then, $10 \mathrm{~g}$ of RCA which measured $<5 \mathrm{~mm}$ was inserted into each beaker. All the beaker batch reactors were continuously shaken using the Orbital Shaker (VWR Standard Orbital Shaker, Model 3500) for 24 hours with $150 \mathrm{rpm}$. The experiment was continued using $20 \mathrm{~g}$ and $30 \mathrm{~g}$ of recycled aggregates with the same size. After that, the experiment continued with the same initial concentrations of phosphorus and dosages of RCA but with different sizes of RCA which measured between 5 to $10 \mathrm{~mm}$ and 10 to $20 \mathrm{~mm}$.

In this study, 144 synthetic wastewater samples were prepared and treated using RCA. Three types of reagents namely, Salt reagent, Ascorbic Acid and Molybdate were prepared before the analysis of Premoval was conducted. The concentrations of the phosphorus in the synthetic wastewater were checked after 24 hours to determine the percentage of phosphorus removal by using the Discrete Analyser (Smart Chem). Figure 6 and 7 show the RCA in the wastewater samples and the treatment process of wastewater respectively.

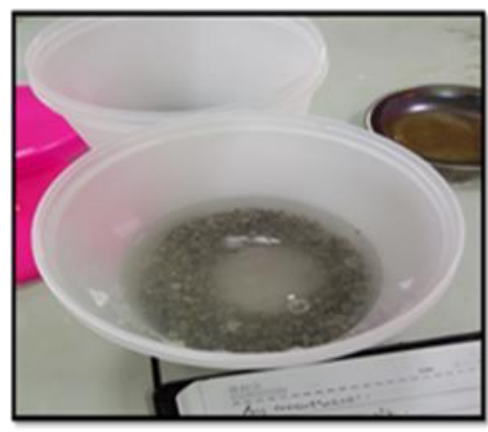

Figure 6 RCA inserted into wastewater

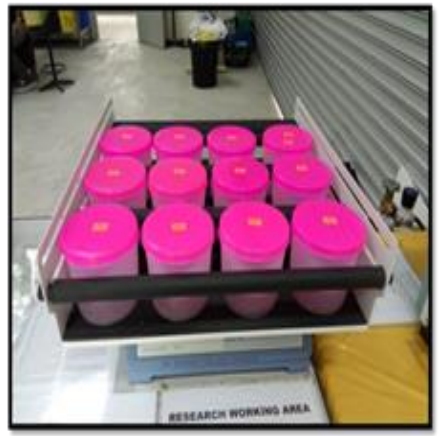

Figure 7 Treatment process

\subsection{ANALYSIS OF SAMPLES BY USING DISCRETE ANALYSER}

For this project, the removal of phosphorus $(\mathrm{P})$ from wastewater was determined by using a Discrete Analyser device (Smart Chem) as shown in Figure 8. DA is an instrument that employs robotics and syringes to aspirate, dispense and mix appropriate amounts of samples and reagent into reaction wells. Before the determination of the P-removal of the samples, a few procedures were conducted. These included the determination of the calibration curve and the preparation of samples and three types of 
reagents as shown in Figure 9. All the procedures should be followed accordingly to avoid errors on the reading of the P-removal during the DA analysis.

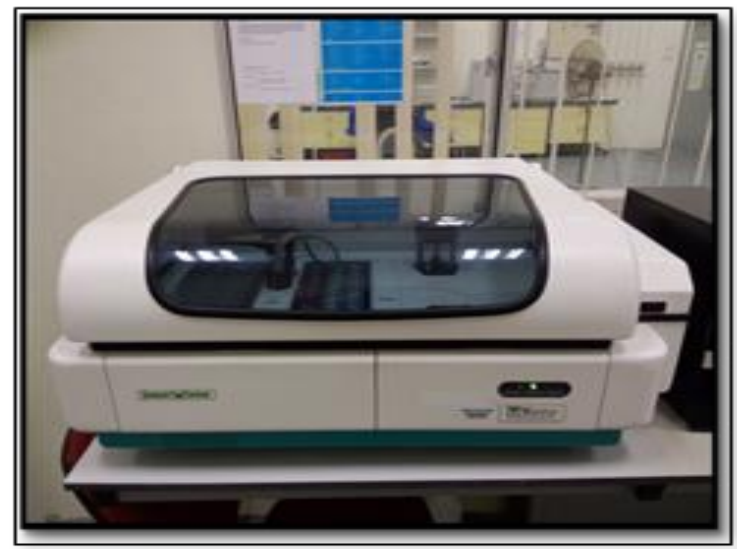

Figure 8 Discrete analyser (Smart Chem)

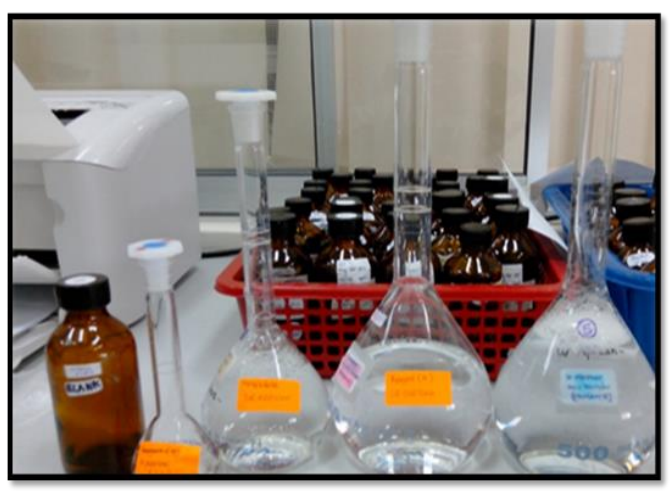

Figure 9 Reagent for DA

\subsection{RESULTS AND ANALYSIS}

\subsection{UPTAKE CAPACITY OF PHOSPHORUS}

For this project, the uptake capacity, $\mathrm{q}$, of phosphorus $(\mathrm{P})$ is the amount of $\mathrm{P}$ absorbed by a unit gram of RCA where the unit of uptake capacity is $\mathrm{mg} / \mathrm{L}(\mathrm{P}) / \mathrm{g}(\mathrm{RCA})$. Observation and calculation on the uptake capacity of $\mathrm{P}$ is to show the ability of RCA as a filter medium in removing $\mathrm{P}$ from wastewater. Figures 10,11 and 12 show the data and analysis of the uptake capacity of P by using RCA.

Figure 10 shows the result of the uptake capacity, q, of $\mathrm{P}$ with different initial concentrations for $10 \mathrm{~g}$, $30 \mathrm{~g}$ and $50 \mathrm{~g}$ of RCA and the RCA size between $0 \mathrm{~mm}$ to $5 \mathrm{~mm}$. For $10 \mathrm{~g}$ of RCA, the uptake capacity of $10 \mathrm{mg} / \mathrm{L}$ of $\mathrm{P}$ was 0.996 while the uptake capacities of $20 \mathrm{mg} / \mathrm{L}$ and $30 \mathrm{mg} / \mathrm{L}$ were 1.539 and 2.470 respectively. For $30 \mathrm{~g}$ of RCA, the uptake capacity of $10 \mathrm{mg} / \mathrm{L}$ of $\mathrm{P}$ was 0.332 while the uptake capacities for $20 \mathrm{mg} / \mathrm{L}$ and $30 \mathrm{mg} / \mathrm{L}$ were 0.551 and 0.869 respectively. Finally, for $50 \mathrm{~g}$ of RCA, the uptake capacity of $10 \mathrm{mg} / \mathrm{L}$ was 0.182 while the uptake capacities for $20 \mathrm{mg} / \mathrm{L}$ and $30 \mathrm{mg} / \mathrm{L}$ were 0.371 and 0.548 respectively. Based on the results, the uptake capacity of $\mathrm{P}$ was found to increase as the initial concentration increases. However, the uptake capacity decreases as the dosage of RCA increases. 
Figure 11 presents the uptake capacity of $\mathrm{P}$ but here the size of RCA used was between $5 \mathrm{~mm}$ to $10 \mathrm{~mm}$. For $10 \mathrm{~g}$ of RCA, the uptake capacity of $10 \mathrm{mg} / \mathrm{L}$ was 0.944 whereas the uptake capacities for $20 \mathrm{mg} / \mathrm{L}$ and $30 \mathrm{mg} / \mathrm{L}$ were 1.255 and 1.5855 respectively. For $30 \mathrm{~g}$ of RCA, the uptake capacity for $10 \mathrm{mg} / \mathrm{L}$ was 0.293 whereas the uptake capacities for $20 \mathrm{mg} / \mathrm{L}$ and $30 \mathrm{mg} /$ were 0.451 and 0.709 respectively. Finally, for $50 \mathrm{~g}$ of RCA, the uptake capacity of $10 \mathrm{mg} / \mathrm{L}$ was 0.175 whereas the uptake capacities of $20 \mathrm{mg} / \mathrm{L}$ and $30 \mathrm{mg} / \mathrm{L}$ were 0.285 and 0.511 respectively. As it can be seen from the graph, it is obvious that $10 \mathrm{~g}$ of RCA has the highest uptake capacity.

Figure 12 is similar with Figure 10 and 11 except that RCA measuring between $10 \mathrm{~mm}$ and $20 \mathrm{~mm}$ was used. In this figure, it was shown that $10 \mathrm{~g}$ of RCA produced the highest uptake capacity. For $10 \mathrm{~g}$ of RCA, the uptake capacities of $10 \mathrm{mg} / \mathrm{L}, 20 \mathrm{mg} / \mathrm{L}$ and $30 \mathrm{mg} / \mathrm{L}$ were $0.874,1.006$ and 1.042 respectively. RCA with $30 \mathrm{~g}$ of dosage produced uptake capacities of $0.300,0.411$ and 0.538 for initial concentrations of $10 \mathrm{mg} / \mathrm{L}, 20 \mathrm{mg} / \mathrm{L}$ and $30 \mathrm{mg} / \mathrm{L}$. Finally, for $50 \mathrm{~g}$ of RCA, the uptake capacity of $10 \mathrm{mg} / \mathrm{L}, 20 \mathrm{mg} / \mathrm{L}$ and $30 \mathrm{mg} / \mathrm{L}$ were $0.174,0.282$ and 0.478 respectively. From Figures 10, 11 and 12, it can be generally observed that the uptake capacity of P decreases as the dosage of RCA increases. Besides that, the uptake capacity of $\mathrm{P}$ increases as the initial concentration increases. These results are similar to the findings by Johansson [7] and Drizo et al., [8]. In their research on limestone as a filter medium, it was shown that the sorption capacity of $\mathrm{P}$ was $0.25-0.3 \mathrm{mg} / \mathrm{g}$ when the initial concentration applied was $5-25 \mathrm{mg} / \mathrm{L}$. Meanwhile, the sorption capacity increased to $0.682 \mathrm{mg} / \mathrm{g}$ when an initial concentration of $40 \mathrm{mg} / \mathrm{L}$ was applied.

Calcium $(\mathrm{Ca})$ content in RCA also affects the removal of P. From the EDX test it was clear that RCA contains $26.60 \%$ of $\mathrm{Ca}$. $\mathrm{Ca}$ is one of the elements for enhancing phosphorus adsorption. The porous surface structure of RCA also influences the ability of RCA to remove P Xiangling et al., [9]. The larger the porosity, the larger the specific surface area where the adsorption mechanism can take place.

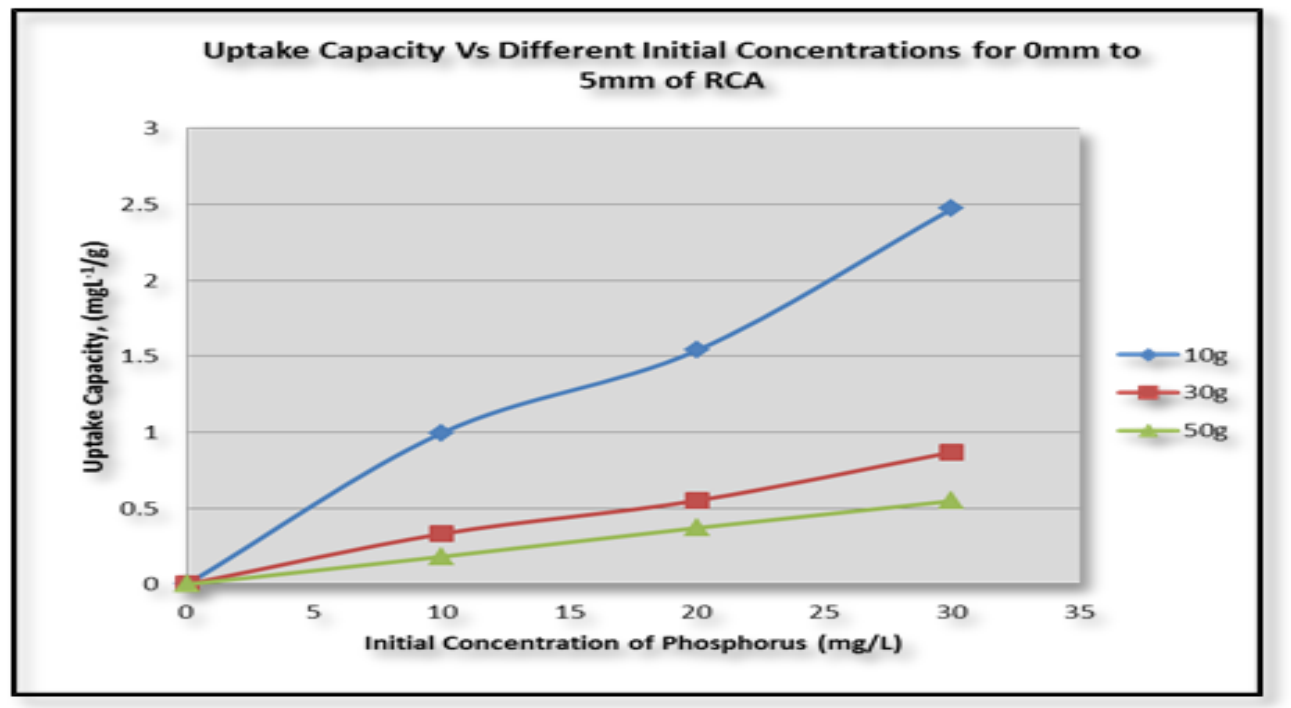

Figure 10 Uptake capacity of $\mathrm{P}$ with different initial concentrations of $\mathrm{P}$ for $0 \mathrm{~mm}$ to $5 \mathrm{~mm}$ of RCA 


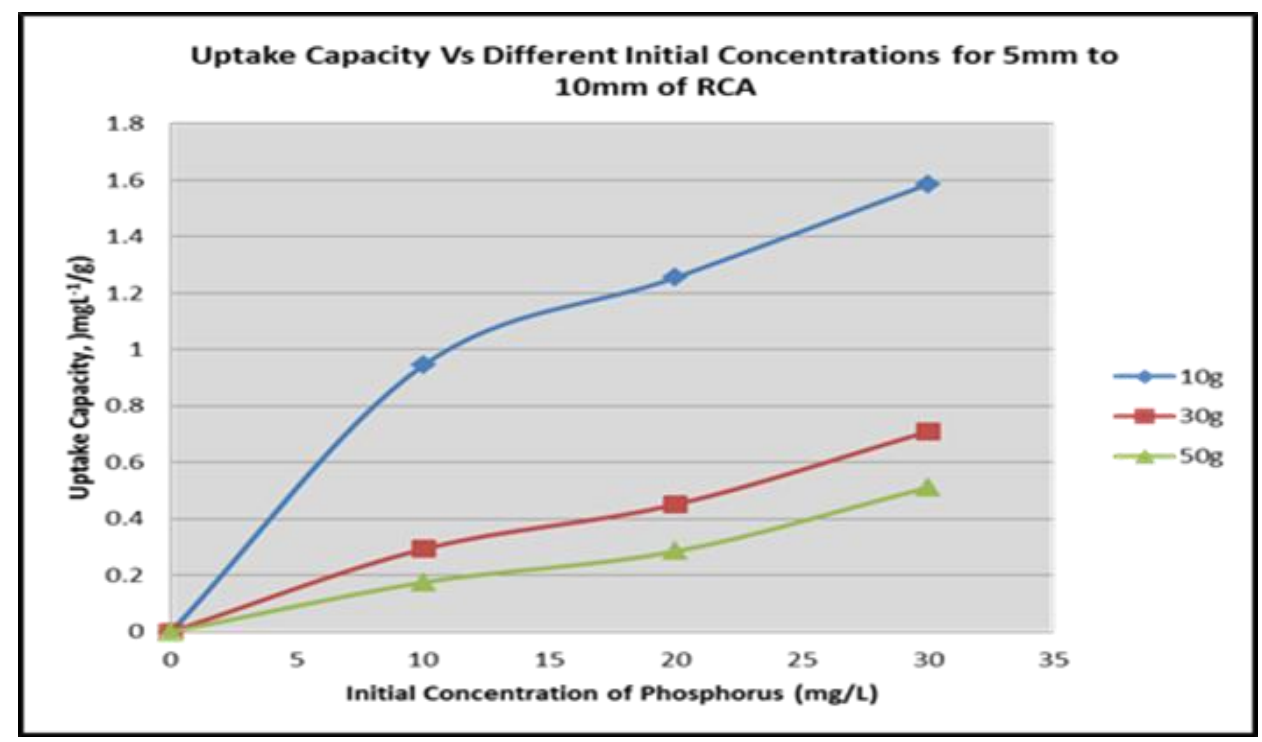

Figure 11 Uptake capacity of $\mathrm{P}$ with different initial concentrations of $\mathrm{P}$ for $5 \mathrm{~mm}$ to $10 \mathrm{~mm}$ of RCA

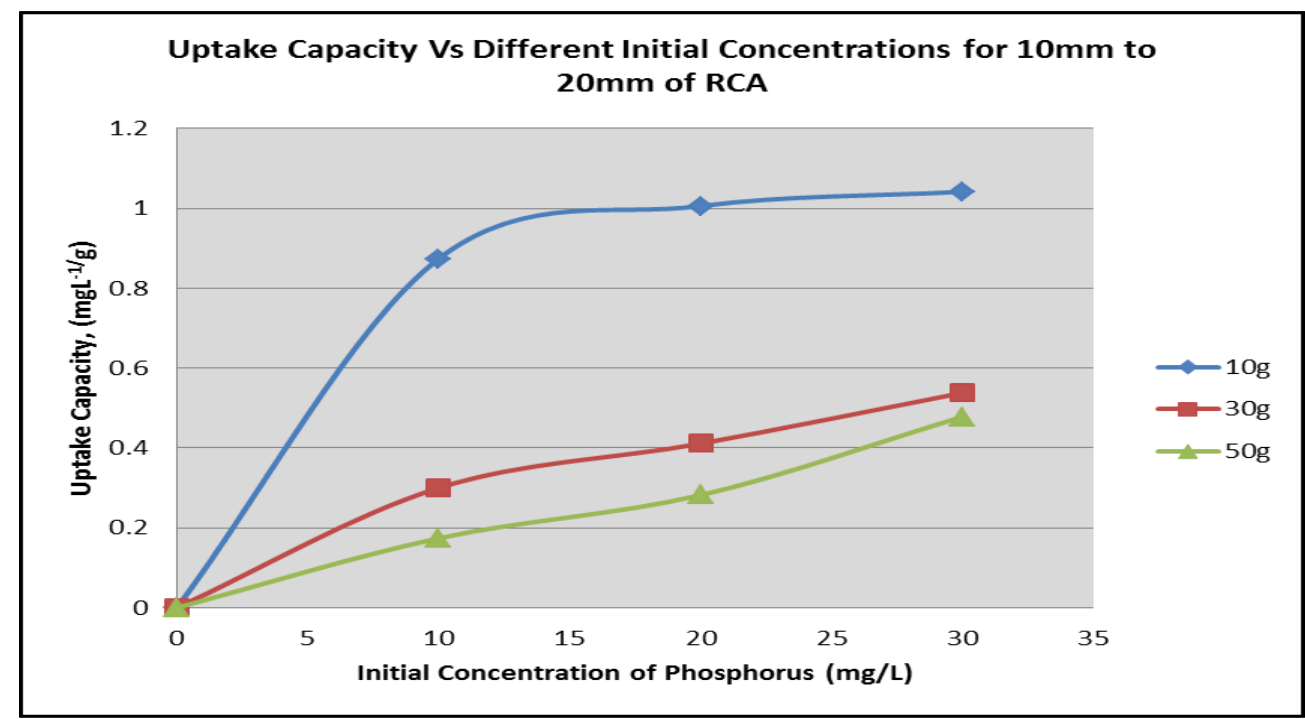

Figure 12 Uptake capacity of $\mathrm{P}$ with different initial concentrations of $\mathrm{P}$ for $10 \mathrm{~mm}$ to $20 \mathrm{~mm}$ of RCA

\subsection{PERCENTAGE OF PHOSPHORUS REMOVAL}

This section discusses the data and analysis of the percentage of P-removal in wastewater throughout the treatment process. Figures 12, 13 and 14 show all the results obtained from the experiments on the percentage of P-removal in wastewater. Equation 2 shows the formula used to calculate the percentage of $\mathrm{P}$ removal.

Where,

Influent: initial concentration;

Effluent: final concentration.

Based on Figure 13, the percentage of $\mathrm{P}$ removal in wastewater was shown with different initial concentrations for $10 \mathrm{~g}, 30 \mathrm{~g}$ and $50 \mathrm{~g}$ of RCA as filter media where the RCA size was between $0 \mathrm{~mm}$ to $5 \mathrm{~mm}$. For the initial concentration of $10 \mathrm{mg} / \mathrm{L}, 10 \mathrm{~g}$ of RCA removed $99.55 \%$ of $\mathrm{P}, 30 \mathrm{~g}$ of RCA removed $99.56 \%$ of $\mathrm{P}$ while $50 \mathrm{~g}$ of RCA removed $99.87 \%$ of $\mathrm{P}$. At this stage the absorption of $\mathrm{P}$ was excellent because almost $100 \%$ of $\mathrm{P}$ was absorbed by RCA. This could be due to the small concentration of P. For 
the initial concentration of $20 \mathrm{mg} / \mathrm{L}, 10 \mathrm{~g}$ of RCA removed $76.95 \%$ of $\mathrm{P}$, while $30 \mathrm{~g}$ of RCA removed $82.65 \%$ of $\mathrm{P}$ and $50 \mathrm{~g}$ of RCA removed $92.86 \%$ of $\mathrm{P}$. This shows that $50 \mathrm{~g}$ of RCA removed the highest amount of P. For the third concentration which was $30 \mathrm{mg} / \mathrm{L}, 10 \mathrm{~g}$ of RCA removed $82.33 \%$ of $\mathrm{P}$, while $30 \mathrm{~g}$ of RCA removed $86.89 \%$ of $\mathrm{P}$ and finally $50 \mathrm{~g}$ of RCA removed $91.39 \%$ of $\mathrm{P}$. Based on the results, the percentage of $\mathrm{P}$ removal increases as the dosage of RCA increases.

Figure 14 shows the percentage of $\mathrm{P}$ removal in wastewater with different initial concentrations for 10 $\mathrm{g}, 30 \mathrm{~g}$ and $50 \mathrm{~g}$ of RCA as filter medium where the RCA size was between $5 \mathrm{~mm}$ to $10 \mathrm{~mm}$. For the initial concentration of $10 \mathrm{mg} / \mathrm{L}, 10 \mathrm{~g}$ of RCA removed $86.78 \%$ of $\mathrm{P}$, while $30 \mathrm{~g}$ of RCA removed $87.83 \%$ of $\mathrm{P}$ and $50 \mathrm{~g}$ of RCA removed $87.42 \%$ of $\mathrm{P}$. For the initial concentration of $20 \mathrm{mg} / \mathrm{L}, 10 \mathrm{~g}$ of RCA removed $62.74 \%$ of $\mathrm{P}$, while $30 \mathrm{~g}$ of RCA removed $67.58 \%$ of $\mathrm{P}$ and $50 \mathrm{~g}$ of RCA removed $71.13 \%$ of $\mathrm{P}$. Meanwhile, for the third concentration which was $30 \mathrm{mg} / \mathrm{L}, 10 \mathrm{~g}$ of RCA removed $52.85 \%$ of $\mathrm{P}$, while $30 \mathrm{~g}$ of RCA removed $70.87 \%$ of $\mathrm{P}$ and finally $50 \mathrm{~g}$ of RCA removed $85.20 \%$ of $\mathrm{P}$. Based on the results, the percentage of $\mathrm{P}$ removal slightly decreased compared to the previous figure where the size of RCA used was $0 \mathrm{~mm}$ to $5 \mathrm{~mm}$. However, the highest dosage of RCA removed the highest percentage of P.

Figure 15 shows the percentage of $\mathrm{P}$ removal with different initial concentrations for $10 \mathrm{~g}, 30 \mathrm{~g}$ and $50 \mathrm{~g}$ of RCA. However, here the size of RCA used was between $10 \mathrm{~mm}$ to $20 \mathrm{~mm}$. For the initial concentration of $10 \mathrm{mg} / \mathrm{L}, 10 \mathrm{~g}$ of RCA removed $87.44 \%$ of $\mathrm{P}$, while $30 \mathrm{~g}$ of RCA removed $89.90 \%$ of $\mathrm{P}$ and $50 \mathrm{~g}$ of RCA removed $86.90 \%$ of P. For the initial concentration of $20 \mathrm{mg} / \mathrm{L}, 10 \mathrm{~g}$ of RCA removed $50.30 \%$ of $\mathrm{P}$, while $30 \mathrm{~g}$ of RCA removed $61.69 \%$ of $\mathrm{P}$ and $50 \mathrm{~g}$ of RCA removed $70.49 \%$ of P. Furthermore, for the third concentration which was $30 \mathrm{mg} / \mathrm{L}, 10 \mathrm{~g}$ of RCA removed $34.73 \%$ of $\mathrm{P}$, while $30 \mathrm{~g}$ of RCA removed $53.84 \%$ of $\mathrm{P}$ and finally $50 \mathrm{~g}$ of RCA removed $79.58 \%$ of $\mathrm{P}$. From this graph, it was shown that $50 \mathrm{~g}$ of RCA absorbed the highest percentage of P. By referring to these graphs, all of them showed that $50 \mathrm{~g}$ of RCA resulted in the highest removal of P. On the other hand, it can be seen that the percentage of P-removal slightly decreases as the initial concentration of $\mathrm{P}$ increases. Based on the acquired results, similarities with the outcomes from Wood and McAtamney [10] were observed where $80 \%$ to $90 \%$ of the initial $\mathrm{P}$ was absorbed by Laterite when concentrations of 5-10 $\mathrm{mg} / \mathrm{L}$ were applied whereas $60 \%$ of the initial $\mathrm{P}$ was absorbed when higher concentrations were applied. The percentage of $\mathrm{P}$ removal efficiency was predominantly affected by the size of the filter medium. This is because the smaller the size of the medium, the greater the surface available for Calcium Oxide dissolution [11].

According to Sønderup, M.J., et al., [12] found that for this catchment the best correlation between precipitation and measured inflow was obtained by using accumulated precipitation for 5 days. Thus, this was most probably due to the number of total removed phosphorus. Besides, in the model, the filter was set up to retain $65 \%$ and $70 \% \mathrm{TP}$, respectively, regardless of the filter material. In terms of TDP retention however, the concrete filter was much better $(60 \%)$ than the traditional sand filter (10\%), probably due to adsorption [11]. These percentages apply only for the water actually percolating through the filter and not for the water in the overflow. It was clearly stated that the concrete filter was an effective filter for the removal of phosphorus. 


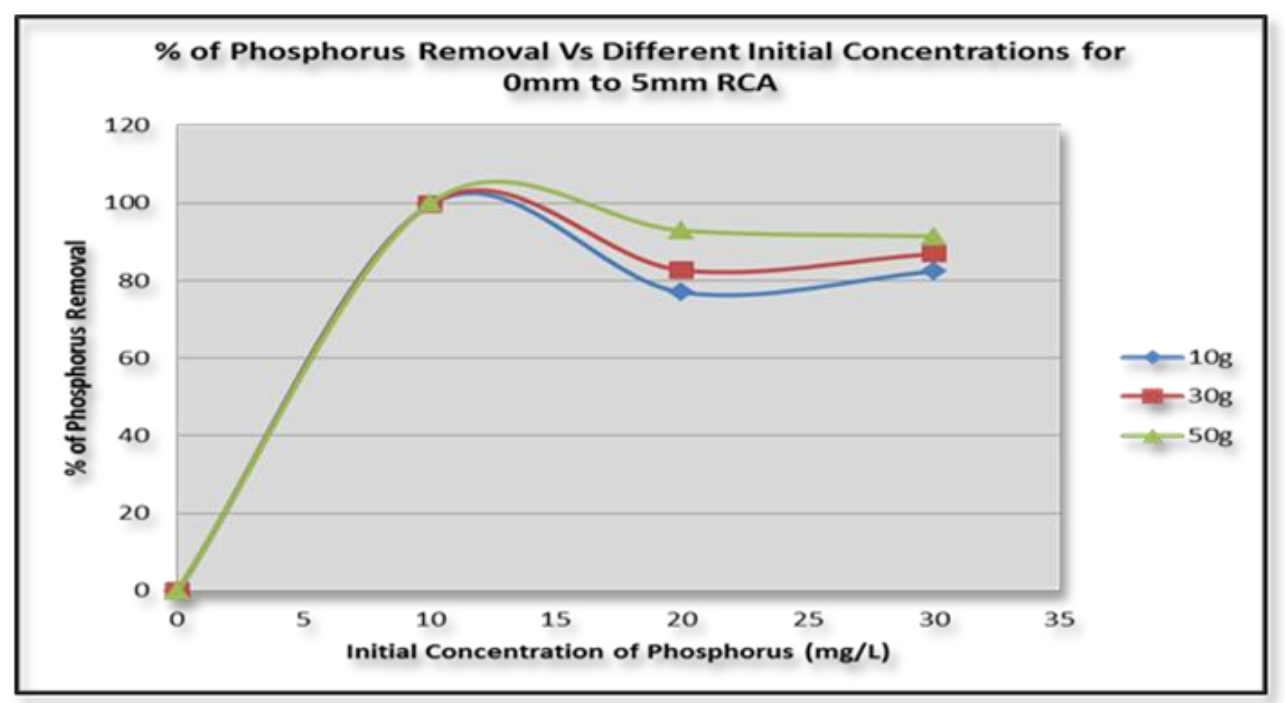

Figure 13 Percentage of $\mathrm{P}$ removal with different initial concentrations of $\mathrm{P}$ for $0 \mathrm{~mm}$ to $5 \mathrm{~mm}$ of RCA

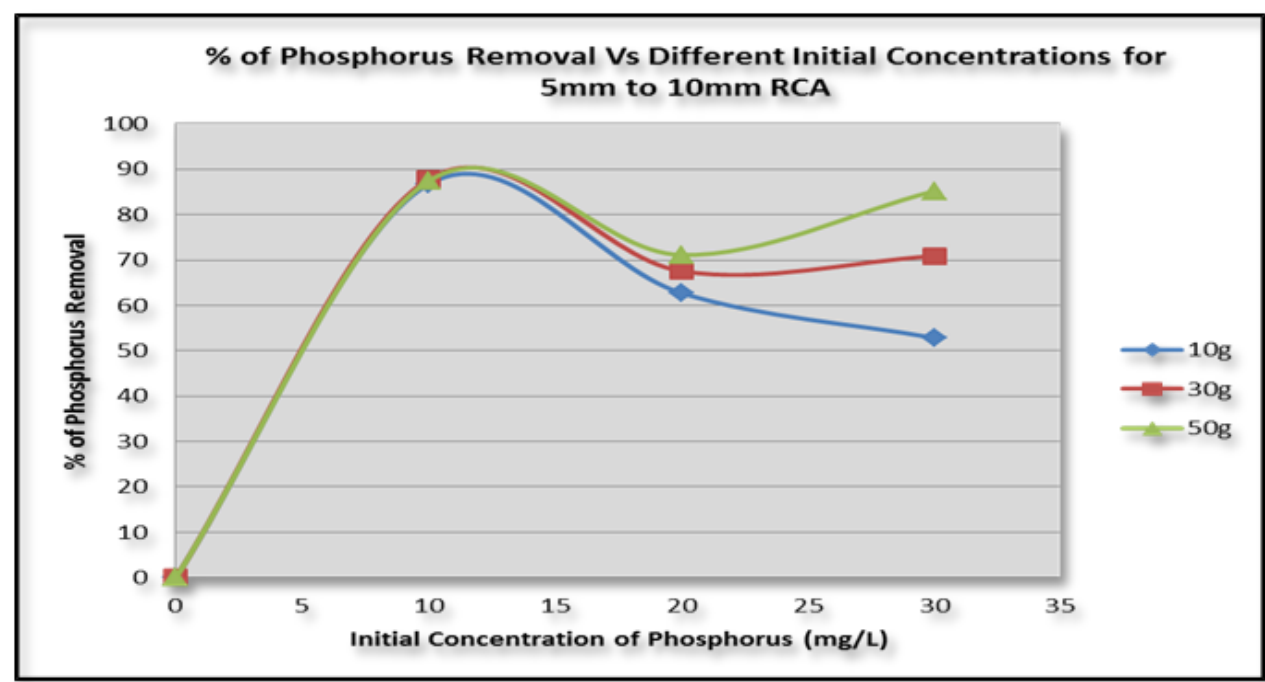

Figure 14 Percentage of $\mathrm{P}$ removal with different initial concentrations of $\mathrm{P}$ for $5 \mathrm{~mm}$ to $10 \mathrm{~mm}$ of RCA

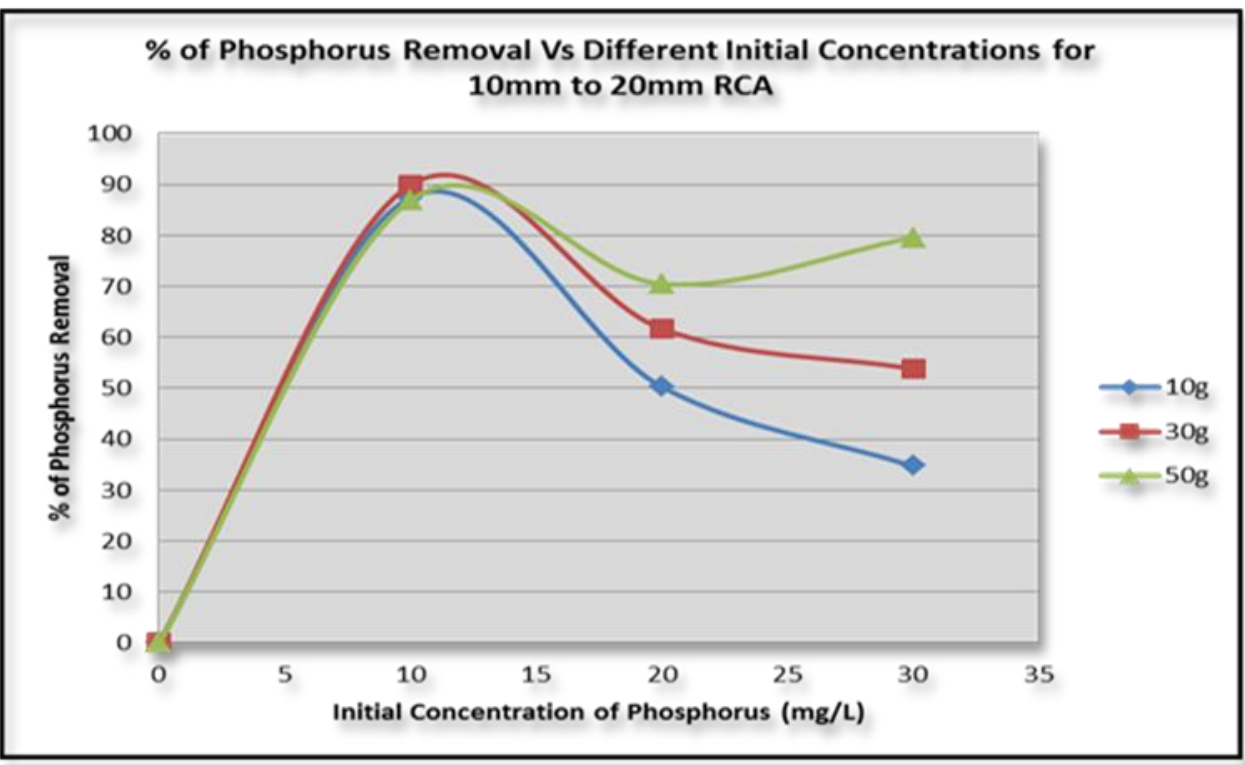

Figure 15 Percentage of $\mathrm{P}$ removal with different initial concentration of $\mathrm{P}$ for $10 \mathrm{~mm}$ to $20 \mathrm{~mm}$ of RCA 


\subsection{TOTAL REMOVAL OF PHOSPHORUS FOR DIFFERENT RCA SIZES}

From Figure 16, the total removal of $\mathrm{P}$ for $10 \mathrm{~g}$ of RCA with different sizes was shown. For RCA measuring between $0 \mathrm{~mm}$ to $5 \mathrm{~mm}$, the total removal values of $P$ with initial concentrations of $10 \mathrm{mg} / \mathrm{L}$, $20 \mathrm{mg} / \mathrm{L}$ and $30 \mathrm{mg} / \mathrm{L}$ were $9.955 \mathrm{mg} / \mathrm{L}, 15.390 \mathrm{mg} / \mathrm{L}$ and $24.698 \mathrm{mg} / \mathrm{L}$. Meanwhile, for RCA measuring between $5 \mathrm{~mm}$ to $10 \mathrm{~mm}, 9.444 \mathrm{mg} / \mathrm{L}, 12.548 \mathrm{mg} / \mathrm{L}$ and $15.855 \mathrm{mg} / \mathrm{L}$ of $\mathrm{P}$ was removed from initial concentrations of $10 \mathrm{mg} / \mathrm{L}, 20 \mathrm{mg} / \mathrm{L}$ and $30 \mathrm{mg} / \mathrm{L}$ respectively. Lastly, for RCA measuring between 10 $\mathrm{mm}$ to $20 \mathrm{~mm}$, the total removal values of $P$ for initial concentrations of $10 \mathrm{mg} / \mathrm{L}, 20 \mathrm{mg} / \mathrm{L}$ and $30 \mathrm{mg} / \mathrm{L}$ were $8.744 \mathrm{mg} / \mathrm{L}, 10.059 \mathrm{mg} / \mathrm{L}$ and $10.418 \mathrm{mg} / \mathrm{L}$ respectively. This graph also shows that the total removal of $\mathrm{P}$ during the treatment process decreases as the size of RCA increases.

Figure 17 shows the total removal of $\mathrm{P}$ for $30 \mathrm{~g}$ of RCA with different sizes. For RCA measuring between $0 \mathrm{~mm}$ to $5 \mathrm{~mm}$, the total $\mathrm{P}$ removal values for $10 \mathrm{mg} / \mathrm{L}$ of $\mathrm{P}, 20 \mathrm{mg} / \mathrm{L}$ of $\mathrm{P}$ and $30 \mathrm{mg} / \mathrm{L}$ of $\mathrm{P}$ were 9.956 $\mathrm{mg} / \mathrm{L}, 16.531 \mathrm{mg} / \mathrm{L}$ and $26.067 \mathrm{mg} / \mathrm{L}$ respectively. For RCA measuring between $5 \mathrm{~mm}$ to $10 \mathrm{~mm}$, the total P removal values for $10 \mathrm{mg} / \mathrm{L}, 20 \mathrm{mg} / \mathrm{L}$ and $30 \mathrm{mg} / \mathrm{L}$ were $8.783 \mathrm{mg} / \mathrm{L}, 13.515 \mathrm{mg} / \mathrm{L}$ and 21.260 $\mathrm{mg} / \mathrm{L}$ respectively. Lastly, for RCA measuring between $10 \mathrm{~mm}$ to $20 \mathrm{~mm}$, the total $\mathrm{P}$ removal values 10 $\mathrm{mg} / \mathrm{L}$ of $\mathrm{P}, 20 \mathrm{mg} / \mathrm{L}$ of $\mathrm{P}$ and $30 \mathrm{mg} / \mathrm{L}$ of $\mathrm{P}$ were $8.990 \mathrm{mg} / \mathrm{L}, 12.338 \mathrm{mg} / \mathrm{L}$ and $16.152 \mathrm{mg} / \mathrm{L}$ respectively. By comparing the results of Figure 16 and Figure 17, the total removal of $\mathrm{P}$ increases as the dosage of RCA increases.

Figure 18 also illustrates the total removal of $\mathrm{P}$ for RCA with different sizes for $50 \mathrm{~g}$ of RCA. For RCA measuring between $0 \mathrm{~mm}$ to $5 \mathrm{~mm}$, the total $\mathrm{P}$ removal values for $10 \mathrm{mg} / \mathrm{L}$ of $\mathrm{P}, 20 \mathrm{mg} / \mathrm{L}$ and $30 \mathrm{mg} / \mathrm{L}$ were $9.087 \mathrm{mg} / \mathrm{L}, 18.571 \mathrm{mg} / \mathrm{L}$ and $27.417 \mathrm{mg} / \mathrm{L}$ respectively. For RCA measuring $5 \mathrm{~mm}$ to $10 \mathrm{~mm}$, the total $\mathrm{P}$ removal values for $10 \mathrm{mg} / \mathrm{L}$ of $\mathrm{P}, 20 \mathrm{mg} / \mathrm{L}$ of $\mathrm{P}$ and $30 \mathrm{mg} / \mathrm{L}$ of $\mathrm{P}$ were $8.742 \mathrm{mg} / \mathrm{L}, 14.226 \mathrm{mg} / \mathrm{L}$ and $25.559 \mathrm{mg} / \mathrm{L}$ respectively. Lastly, for RCA measuring $10 \mathrm{~mm}$ to $20 \mathrm{~mm}$, the total $\mathrm{P}$ removal values for $10 \mathrm{mg} / \mathrm{L}$ of $P, 20 \mathrm{mg} / \mathrm{L}$ of $P$ and $30 \mathrm{mg} / \mathrm{L}$ were $9.093 \mathrm{mg} / \mathrm{L}, 16.946 \mathrm{mg} / \mathrm{L}$ and $25.012 \mathrm{mg} / \mathrm{L}$ respectively. From Figures 16, 17 and 18, the concentration of $\mathrm{P}$ absorbed increases as the dosage of RCA increases. According to Nassar [13], 20\% of cement paste was found attached to the surface of RCA. Cement paste contains a high amount of $\mathrm{CaO}$. This could verify the fact that the highest dosage of RCA removed the highest amount of P. Meanwhile, it also shows that RCA with the smallest size absorbed more P compared to RCA of larger sizes. According to Hansen [14], the water absorption capacity of RCA varies depending on the amount of cement paste attached to the surface of the aggregate particles. From the findings, the water absorption capacity of RCA is higher for smaller particle sizes since the higher the specific surface area, the higher the cement content. In addition, coarse RCA has a water absorption capacity of $7 \%$ while fine RCA has a water absorption capacity of $13 \%$. This proves that smaller sized RCA contains a high amount of cement paste that is able to react more with $\mathrm{P}$ compared to larger sized RCA.

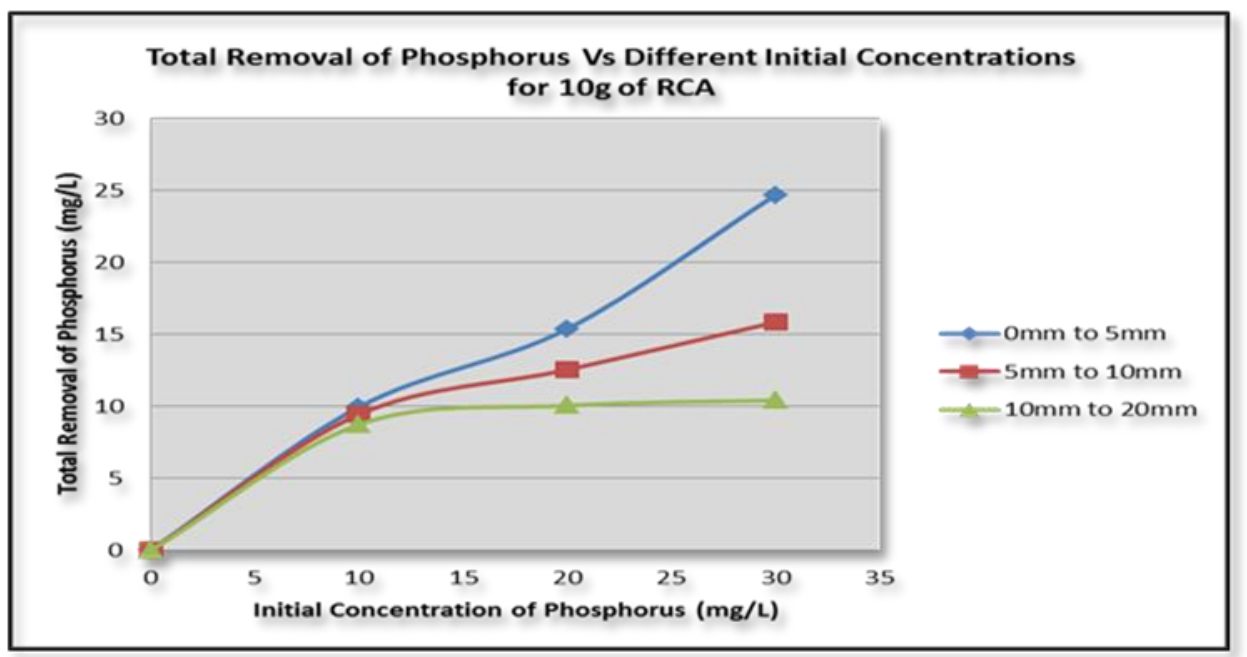

Figure 16: Total removal of $\mathrm{P}$ with different initial concentration for $10 \mathrm{~g}$ of RCA 


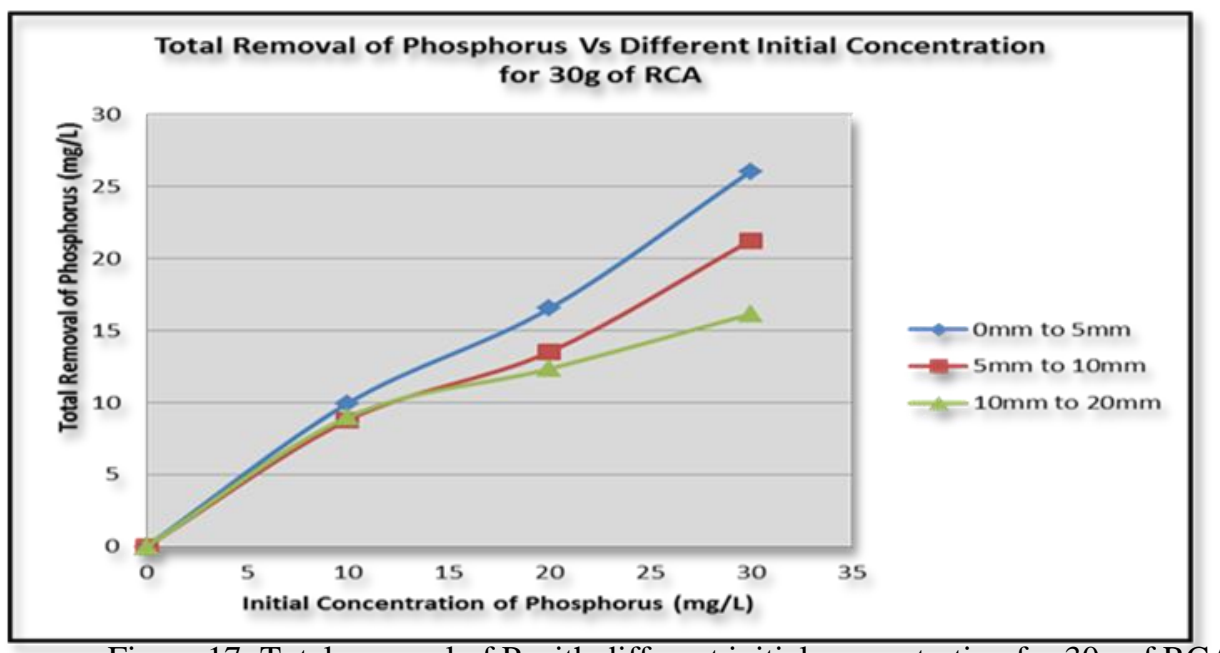

Figure 17: Total removal of $\mathrm{P}$ with different initial concentration for 30g of RCA

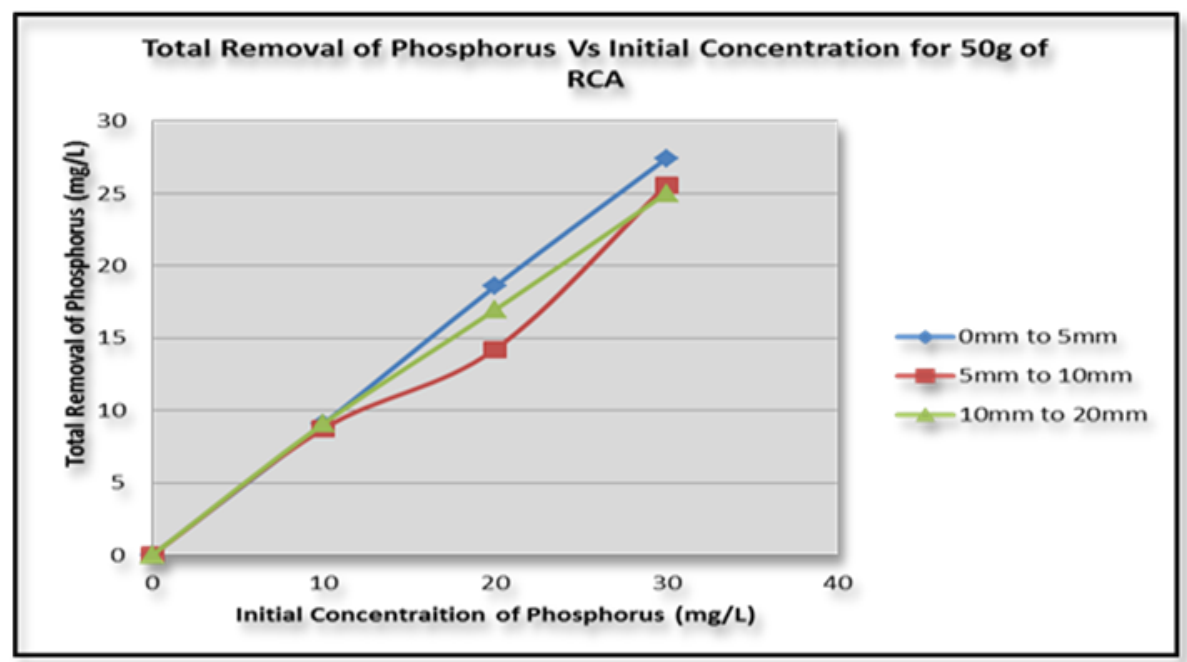

Figure 18: Total removal of $\mathrm{P}$ with different initial concentration for 50g of RCA

\subsection{CONCLUSIONS}

Based on the experimental results and data analysis, the objectives of this study have been achieved. Hence, according to the analysis, a number of conclusions can be made.

Firstly, the objective of this project was to investigate the uptake capacity of RCA with different dosages of RCA used for phosphorus removal. The experiment results show that RCA with the lowest dosage has the highest uptake capacity. In addition, it shows that RCA could be a potential filter medium for Premoval in wastewater where the uptake capacity range of RCA is $0.17-2.47 \mathrm{mg} \mathrm{P} / \mathrm{g}$.

The second objective for this project was to measure the percentage of P-removal in wastewater by using different sizes of RCA and different initial concentrations of phosphorus. Based on the results obtained from the experiments, RCA with the smallest size and the lowest initial concentration of $\mathrm{P}$ which are 0 $\mathrm{mm}$ to $5 \mathrm{~mm}$ and $10 \mathrm{mg} / \mathrm{L}$, respectively, achieved the highest percentage of P-removal which was $99.56 \%$.

The third objective for this project was to determine the relationship of different RCA sizes with different initial concentrations of phosphorus towards the percentage of P-removal. From the results, the 
percentage of P-removal decreases as the initial concentration of $\mathrm{P}$ increases while the percentage of $\mathrm{P}$ removal increases as the size of RCA decreases.

Thus, as conclusion for this project, RCA has been proven as one of the potential filter media used for P-removal in wastewater. This is because RCA achieved the highest percentage of P-removal which was $99.56 \%$. This finding could benefit the environment by reducing the discharge of $\mathrm{P}$ from wastewater to water bodies which could lead to eutrophication. Other than this, the use of RCA as a filter medium seems to be a promising contribution towards the sustainability of the construction industry.

\section{ACKNOWLEDGEMENT}

The authors gratefully acknowledge Universiti Tun Hussein Onn Malaysia and the Ministry of Higher Education for providing financial support through the Fundamental Research Grant Scheme (FRGS), Vot 1618.

\section{REFERENCES}

[1] DEFRA. (2006). Review of England's waste strategy-a consultation document, summary ofresponses to the consultation. London: Department for Environment, Food and Rural Affairs.

[2] Tam, V. W. Y. (2009). Comparing the implementation of concrete recycling in the Australian and Japanese construction industries. Journal of Cleaner Production 17.7: 688-702.

[3] Federal Highway Administration (FHWA). (2004). Transportation Applications of Recycled Concrete Aggregates. State of the Practice National Review.

[4] Recycling Technology Assistance Partnership (ReTAP) (1998). Quality Control for Recycled Concrete as a Structural Fill Material.

[5] Adnan. S.H, Abdul Rahman, I, .Mohd Saman, H. (2014). Enhancing the performance of Recycled Aggregate Concrete Using Micronized Biomass Silica. INCIEC 2014: Proceedings of the International Civil and Infrastructure Engineering Conference 2014, Springer Singapore.

[6] Vymazal, J., Brix, H., Cooper, P.F., Green, M.B., Haberl, R. (Eds.), (1998).Constructed Wetlands for Wastewater Treatment in Europe. Backhuys Publishers, Leiden, The Netherlands.

[7] Johansson, L. (1999). Industrial by-products and natural substrata as phosphorus sorbents. Environmental Technology 20, 309-316.

[8] Drizo, A., Frost C.A., Grace J. Smith, K.A., (1999). Physico-chemical screening of phosphate-removing substrates for use in constructed wetland systems. Water Res. 33 (17): 3595-3602.

[9] Xiangling, Z., Lu, G.,Hualing, H., Yinghe, J., Meng., L., Yujie, L.(2016). Removal of phosphorus by the core-shell bio-ceramic/Zn-layered double hydroxides (LDHs) composites for municipal wastewater treatment in constructed rapid infiltration system. Water Research, 96: 280-291.

[10] Wood, R.B., McAtamney, C.F. (1996). Constructed wetlands for waste water treatment: the use of laterite in the bed medium in phosphorus and heavy metal removal. Hydrobiologia 340, 323-331.

[11] Chazarenz, M., Surasyh, H., \& Deskon, S. (2017). Biological phosphorus removal process for wastewater treatment. International Conference of Science, 27.

[12] Sønderup, M.J Maier, Egemose, S. \& Mogens R. Flindt, (2013).Cardiovascular Research. Modeling phosphorus removal in wet ponds with filter zones containing sand or crushed concrete.

http://doi.org/10.1016/j.cardiores.2006.11.005

[13] Nassar and Soroushian (2012). Strength and durability of recycled aggregate concrete containing milled glass as partial replacement for cement. Construction and Building Materials; 29: 368-377.

[14] Hansen, T.C., Narud H. (1983) Strength of recycled concrete made from crushed concrete coarse aggregates. Concr Int- Des Constr : 5(1):79-83. 